Check for updates

New York

Cite this as: BMJ 2020;370:m2988 http://dx.doi.org/10.1136/bmj.m2988 Published: 24 July 2020

\section{Covid-19: US cases are greatly underestimated, seroprevalence studies suggest}

\author{
Janice Hopkins Tanne
}

Several seroprevalence studies suggest that US covid-19 infections are many times higher than the reported number, which was close to four million as of 23 July.

At most of the sites in a study from the Centers for Disease Control and Prevention reported in JAMA Internal Medicine, ${ }^{2}$ "it is likely that greater than 10 times more SARS-CoV-2 infections occurred than the number of reported covid-19 cases ... The findings may reflect the number of persons who had mild or no illness or who did not seek medical care or undergo testing but who still may have contributed to ongoing virus transmission in the population.”

The study tested residual serum samples from two commercial laboratories. The samples came from 16025 people of all ages taken from 23 March to 12 May at 10 geographical sites in the US-the San Francisco Bay area, Connecticut, south Florida, Louisiana, the Minneapolis-St Paul-St Cloud metro area in Minnesota, Missouri, the New York City metro area, the Philadelphia metro area, Utah, and western Washington State. The samples had been collected for routine screening (such as for cholesterol screening) or for clinical management. They were de-identified and tested at the Centers for Disease Control and Prevention for antibodies to the virus, by a screening assay followed by a confirmatory assay on apparently reactive specimens.

\section{Herd immunity}

The researchers compared the number of estimated cases in the population, based on their seroprevalence study, with the reported cases in the area. They found that seroprevalence showed six times as many infections as reported in Connecticut and 24 times as many in Missouri. Such testing showed previous covid-19 infection in $1 \%$ of people in San Francisco and about $6.9 \%$ in New York City.

Although most people in the 10 geographic areas had not been infected, "The estimated number of infections ... was much greater than the number of reported cases in all sites," the authors wrote. As people often do not know whether they are infected with covid-19, the authors said that the public should continue to follow guidelines for wearing masks, social distancing, handwashing, and staying home when ill.

In an accompanying editorial two Harvard professors wrote that the study "rebukes the idea" that herd immunity would impede the spread of covid-19 in the US because the seroprevalence found in the study was far below the $60-70 \%$ needed for herd immunity. Active surveillance with polymerase chain reaction or antigen based testing "is urgently needed to blunt the trajectory of the epidemic in the US," they said, calling for testing of 4.3 million people a day to help suppress further transmission. ${ }^{3}$

\section{Infections missed}

Two studies published in Morbidity and Mortality (MMWR) looked at local seroprevalence rates. A door-to-door study in two counties in metropolitan Atlanta, Georgia, found an estimated 2.5\% seroprevalence rate for SARS-CoV-2 antibodies. However, only about half of people testing seropositive recalled having a covid-19-like illness.

"These findings highlight that many SARS-CoV-2 infections would have been missed by case-based surveillance," the authors wrote. They also showed that most people in the area had not been infected. The authors concluded that preventive strategies such as social distancing, wearing masks, and handwashing "remain essential to controlling the spread of SARS-CoV-2 in the community."4

A similar finding-low prevalence, unidentified infections, and the need to continue preventive measures-came from an Indiana study published in MMWR. Indiana, which has a population of 6.73 million, seems to be the only state to have conducted a random sample study of the population at a given point in time.

That study found a seroprevalence rate of $2.8 \%$; however, $44 \%$ of people testing positive in the random sample study said that they had no symptoms during the preceding two weeks. Again, the authors concluded that most state residents remained susceptible and should continue preventive measures. ${ }^{5}$

1 Center for Systems Science and Engineering (CSSE) at Johns Hopkins University. Covid-19 dashboard. 2020. https://gisanddata.maps.arcgis.com/apps/opsdashboard/index.html\#/bda7594740fd40299423467b48e9ecf6.

2 Havers FP, Reed C, Lim T, et al. Seroprevalence of antibodies to SARS-CoV-2 in 10 sites in the United States, March 23-May 12, 2020. JAMA Intern Med2020, published online 21 Jul. https://jamanetwork.com/journals/jamainternalmedicine/fullarticle/2768834.

3 Brown TS, Walensky RP. Serosurveillance and the Covid-19 epidemic in the US. JAMA Intern Med 2020, published online 21 Jul. https://jamanetwork.com/journals/jama/fullarticle/2768835. 
4 Biggs HM, Harris JB, Breakwell L, et al. Estimated community seroprevalence of SARS-CoV-2 antibodies-Two Georgia counties, April 28-May 3, 2020. MMWR Morb Mortal Wkly Rep 2020, published online 21 Jul. https://www.cdc.gov/mmwr/volumes/69/wr/mm6929e2.htm?s_cid=mm6929e2_w.

5 Menachemi N, Yiannoutsos CT, Dixon BT, et al. Population point prevalence of SARS-CoV-2 infection based on a statewide random sample-Indiana, April 25-29, 2020. MMWR Morb Mortal Wkly Rep 2020, published online 24 Jul. https://www.cdc.gov/mmwr/volumes/69/wr/pdfs/mm6929e1-H.pdf.

This article is made freely available for use in accordance with BMJ's website terms and conditions for the duration of the covid-19 pandemic or until otherwise determined by BMJ. You may use, download and print the article for any lawful, non-commercial purpose (including text and data mining) provided that all copyright notices and trade marks are retained. 